\title{
Weight Parameters and Green Tea Effect; A Review
}

\author{
Yusra Hussain ${ }^{1}$, Faizan Ghani ${ }^{2}$, Munawar Ali ${ }^{3}$, Muhammad Imran ${ }^{*}, 4$, Aamira Hashmi ${ }^{5}$, Wajahat Hussain ${ }^{6}$, Muhammad Hashim Raza ${ }^{4}$ \\ ${ }^{1}$ Mayo Hospital Lahore, 54000, Pakistan \\ ${ }^{2}$ District Headquarter Hospital, Toba Take Singh, 36050, Pakistan \\ ${ }^{3}$ Bahawal Victoria Hospital, Bahawalpur, 63100, Pakistan \\ ${ }^{4}$ District Headquarter Hospital, Layyah, 31050, Pakistan \\ ${ }^{5}$ District Headquarter Hospital, Muzaffargarh, 34200, Pakistan \\ ${ }^{6}$ Tehsil Headquarter Hospital, Kallar Syedan, District Rawalpindi, 47520, Pakistan
}

\section{A R T I C L E I N F O}

Article history:

Received: 09 April, 2018

Accepted: 26 May, 2018

Online: 31 May, 2018

Keywords :

Green tea extract (GTE)

Weight loss

Weight reduction

Overweight

Obesity

\begin{abstract}
A B S T R A C T
The objective was to review and add literature whether green tea is helpful for weight reduction. Reviewing the randomized, double-blind, placebo-controlled trials to compare green tea extracts for weight loss from various online sources including Ovid MEDLINE, PubMed, and Cochrane databases studies published in 2006, 2007 and 2008 in English language were considered. In each of the three studies, baseline measurements were taken and analyzed of the research participants. Measurements of total body weight, BMI with reference to age, hip and waist circumference were measured at the interval of 4 weeks i.e. 0 week (0 month), 4th week (1 month), 8th week (2 month), 12th week (3 month) were taken. All the research work analyzed and reviewed showed that a part of some minor changes no major changes were observed to prove the significance of green tea as a single agent for reducing weight. An increase in body energy expenditure was observed which leads to increase in appetite by the subjects but no adverse effects were noted. After detail review and analysis, the results showed that green tea have no significant effect on the weight reduction as a single agent.
\end{abstract}

\section{Introduction}

Obesity is a medical term defined as "having excessive amount of body fats leading to potentially hazardous health conditions". Obesity in term of Body Mass Index (BMI) is defined as "body weight of a person divided by height square root". A person will be overweight, if the average value of BMI is above $30 \mathrm{~kg} / \mathrm{m} 2$, while normal average range of BMI is $25-30 \mathrm{~kg} / \mathrm{m} 2$. Some Asian countries use even less than average value of range. Obesity has a potential hazard of causing serious medical conditions specially heart disease, diabetes type 2, obstructive sleep apnea, certain types of cancer, disorders of depression and osteoarthritis (OA) [1]. Most common cause of obesity is no physical activity, excessive eating of fatty food, and junk food, some people also have a genetic susceptibility of being obese. A few cases are caused primarily by genes, endocrine disorders, medicine or mental disorders. A misconception that obese people can gain more weight even with eating less is not correct. Rather people with more fats have high

\footnotetext{
*Muhammad Imran, DHQ Hospital, Layyah, imranmerani247@gmail.com
}

body energy expenditure than a person who is of same age and height within a normal range of BMI, as an obese person needs to maintain more body mass. It can be prevented and treated with simple diet modifications in eating behavior and physical activity. Diet modifications such as less consumption of fats and high consumption of high fiber diet, and physical activity like regular exercise and walk can prevent and treat obesity [2]. Obesity is the major preventable cause of morbidity and complications which can lead to death world-wide. Its rate is increasing in adult and children day by day. In the year 2015, 650 million adult (12\%) and 100 million children of the world population were obese. Obesity is more common in women than men. Authorities consider it as a major problem faced by people of 21 century and a major drawback from latest inventions [3]. Obesity is characteristic body change observed in high number in people of modern world (particularly in the western world), though it was seen as a symbol of wealth and prosperity at other times in history and still is considered at some parts of the world. In 2013, the American Medical Association classifies obesity as a disease requiring 
treatment [4]. Obesity, weight more than the average BMI accounts for a lot of hospital visits. In 2008, the report stated that the obesity alone account for over $8.1 \%$ of out- patient visits. The caring cost of such people takes a toll on the society. Researchers have suggested that these individual's medical expense may have reached as high as $\$ 80$ billion [5].

There are a few medications which are given to people with serious weight problem not controlled by eating habits and where the benefit out weights the risk involved; never the less medication have adverse effects that cannot be neglected. Also, non-FDA approved drugs are available in the market which has a lot of serious and potentially complicated side effects [6]. While there are a lot of different options in term of treatment, patients often want to have convenient, cost-effective and simple methods to aid their problem. Tea is historically used as a medication. Especially in Asian countries like China and Japan a lot of medicinal use of tea is described in details. Green tea contains two very important components which are often published as a solution for weight problems as green tea is a natural supplement if it could be the solution then it will be the safest and easiest way [7].

\subsection{Objective}

- The objective is to analyze effects of green tea for its effectiveness in weight reduction.

\section{Methods}

All the selected three studies meet the criteria of subjects as women and men, all having a high BMI and of the age group of 15- 40. Green tea extract was prepared in a capsule form. The treatment groups were compared to control groups given visually matched placebo. Parameters including weight, body mass index, circumference of waist, and circumference of hip measurement. The studies were double-blind, randomized, and placebocontrolled. In the study [8], which took place at Khon Kaen University in Thailand, selected participants were students of medicine faculty. All the participants in the research were fully informed about the detail of the study and their consent was taken. They were instructed to maintain their normal diet and daily habits as well as physical activity. A capsule was given to them to take one hour after each meal (Each capsule contain an extract obtained by boiling $5 \mathrm{gm}$ of green tea for a period of $15 \mathrm{~min}$ at $100 \mathrm{~F}$ ). Time was specified in order to maintain the compliance by the participants.

First study reviewed was performed [9], in Maastricht University at Netherlands. In this research, selection of participants was done via an advertisement in the local newspaper to search for the willing participants for the trail. At first, subjects were instructed to make a chart of their daily food intake to measure the average amount caloric intake by the subjects. Than after calculating average caloric intake by each person they were told to keep their food intake in the range, and continue their daily routine.

Table 1: Demographics of included studies

\begin{tabular}{|c|c|c|c|c|c|c|c|c|}
\hline S No & Study & Type & \# Pts & Age (yrs.) & Inclusion Criteria & Exclusion Criteria & W/D & Interventions \\
\hline 1 & [8] & $\mathrm{RCT}$ & 75 & $\begin{array}{l}\text { Males } 35-55 \\
\text { Females post- } \\
\text { Meno }>1 \mathrm{yr} \text {. }\end{array}$ & Male $35-55$ yr. female post-meno $>1 \mathrm{yr}$ & $\begin{array}{c}\text { History of metabolic } \\
\text { disease/ Systemic disease } \\
\text { History of Prescribed } \\
\text { medic- } \\
\text {-Regular exercise Ave- } \\
\text { energy expenditure daily > } \\
8373.6 \mathrm{~kJ} / \text { day } \\
\text { History of tea / caffeine } \\
\text { Allergic reactions }\end{array}$ & 13 & $\begin{array}{l}250 \text { GTE } \\
\text { CAPSULE TIB } \\
\text { after all } 3\end{array}$ \\
\hline 2 & [9] & $\begin{array}{l}\text { RCT Double } \\
\text { Blind, Placebo } \\
\text { Controlled }\end{array}$ & 50 & $25-60$ & $\begin{array}{l}\text { female (25-50) } \\
\text { Overweight, BMI btw } 20-35 \mathrm{~kg} / \mathrm{m} 2 \\
\text { initial screening }\end{array}$ & $\begin{array}{c}\text { Health issues Heavy } \\
\text { smokers regular medicines } \\
\text { use allergic } \\
\text { heavy alcohol use caffeine } \\
>250-450 / \text { day }\end{array}$ & 1 & GTE Capsule \\
\hline 3 & [10] & $\begin{array}{l}\text { RCT Double } \\
\text { Blind, Placebo } \\
\text { Controlled }\end{array}$ & 150 & $15-55$ & $\begin{array}{c}\text { Females }(15-55 \mathrm{yr}) \\
\text { BMI }>28 \mathrm{~kg} / \mathrm{m} 2\end{array}$ & $\begin{array}{c}\text { cardiac disease endocrine } \\
\text { problems } \\
\text { pregnancy } \\
\text { lactation } \\
\text { stroke/inability to exercise } \\
\text { Weight control } \\
\text { management in } 3 \text { months } \\
\text { Other condition unsuitable } \\
\text { as recommendation }\end{array}$ & 2 & GTE Capsule \\
\hline
\end{tabular}

Table 2- Efficacy of Green Tea Extract in Weight Reduction

\begin{tabular}{|c|c|c|c|c|c|c|c|}
\hline S No & Study & GTE group Reduction in Parameters & Placebo group reduction in parameters & $p$-value & RRI & ARI & NNH \\
\hline 1 & [8] & 2.5 & 2.1 & $<0.05$ & $0 *$ & $0 *$ & $0 *$ \\
\hline 2 & [9] & 4.2 & 4.1 & $<0.001$ & 0* & $0 *$ & $0^{*}$ \\
\hline 3 & [10] & 0.3 & 0.2 & 0.73 & 0.5 & 0.3 & 26 \\
\hline
\end{tabular}




\section{Y. Hussainlet al. / Advances in Science, Technology and Engineering Systems Journal Vol. 3, No. 3, 104-107 (2018)}

Second study conducted [10], at The Taipei Hospital, Taiwan for one year. A trial on hundred subjects was done. After selection, subjects were given instructions about their eating habits and an informed consent was taken. A capsule was given to each subject and they were required to come after a month. Inclusion and exclusion criteria were followed by all three studies.

Finally, the third study reviewed [8], which included females with one year postmenopausal and male on an average age of 4050 years old, with body mass index of $26 \mathrm{~kg} / \mathrm{m} 2$ or greater. Subjects having a history of any metabolic or systemic disease or on daily medications, and energy expenditure greater than 8373.6 $\mathrm{kJ} /$ day, or specific history of tea and green tea hypersensitivity were not included.

In [9], the authors included females 18 to 50 years of age with a body mass index of $28 \mathrm{~kg} / \mathrm{m} 2$ to $35 \mathrm{~kg} / \mathrm{m} 2$. Initial screening was done and subjects who were of good health and no systemic and metabolic disease. Candidates with moderate tea and coffee intake and a minimum alcohol intake were selected. Females ages $14-55$ and a body mass index of $23 \mathrm{~kg} / \mathrm{m} 2$ or greater were included in the Hsu et al study. Subjects with endocrine disease, heart disease, allergic or immunological diseases, high liver or renal profile values, pregnant women or lactating mothers, childbirth within six months, stroke history, inability to exercise were excluded.

All the articles searched for the review were published in peerreviewed journals in English language. All literature searches were done using Ovid MEDLINE, PubMed, and Cochrane Databases. Inclusion and exclusion criteria selected for the analysis were POEM, randomized controlled trials, and studies published in 2005 or later. For statistics evaluation in the study p-value, relative risk increase (RRI), absolute risk increase (ARI), and numbers needed to harm (NNH) were used

\subsection{Outcome Measured}

The primary outcome of the studies showed a change in baseline parameters of weight in all three studies. Parameters of the body weight were defined as weight, body mass index, circumference of the waist, and circumference of the hip. Quantitative measurements were calculated in percent reduction of all the parameters at different time intervals throughout the trails. All the parameter measurements were standardized by measuring them in fasting state of the subject in all three studies. Secondary effects of the trail were also recorded as well. In [8], the authors measured level of hunger and the fullness on visual analog scales, resting energy expenditure and substrate oxidation, blood pressure and heart rate, urine VMA levels, and leptin levels. In [9], the authors measured systolic and diastolic blood pressure changes and also record changes in parameters of blood such as TG, LDL, HDL, leptin, and glucose levels. In [10], the authors measured hormone peptide levels throughout the trail including insulin, adiponectin, leptin, and ghrelin.

\section{Results}

The results concluded after the study was done on continuous data. The continuous data in [10], study can be converted to dichotomous form. The data obtained from the studies were presented and it was decided to treat analysis with exception of the participants who lost the follow ups. In [8], the authors reported weight loss of $2.5 \mathrm{~kg}$ and $1.8 \mathrm{~kg}$ in the green tea extract and control groups, respectively. The p-value over time was statistically significant between groups $(p<0.05)$. During these studies, side effects were not seen in both controlled and experimental groups. Therefore, an exact value which can be harmful cannot be calculated. (Table 2). In [9], the authors reported weight reduction of $4.0 \mathrm{~kg}$ and $4.5 \mathrm{~kg}$ in green tea extract and control groups, respectively. The data for the study which was considered statistically significant is $(p<0.001)$. In the time period of study both groups had no adverse side effects, so no value can be calculated which may produce harm (Table 2).

In [10], the authors reported weight reduction of $0.2 \mathrm{~kg}$ and 0.1 $\mathrm{kg}$ in the GTE and control groups, respectively. The data was not statistically significant $(p=0.72)$. The absolute risk increase (ARI) was calculated to be $0.7 \%$ and the relative risk increase (RRI) was calculated to be $0.05 \%$. In this study none of the subjects withdraw from the experiment but there were some subjects who observed side effects of the trial, therefore a number which can cause harm was also concluded. This study determined that the number needed to harm (NNH) was 25 patients using the dosage of $400 \mathrm{mg}$ TID (Table 2).

One of the three trails showed subjects with mild adverse effect. In [10], 4 subjects experienced mild constipation and 2 experienced abdominal discomforts. Three subjects were found to experience mild nausea but no vomiting or other abnormalities were present in placebo treatment.

In all three trails, subjects were monitored in their special facilities where weight parameters were taken with accuracy and same measuring tools were used throughout screening days were also specified. In [8], the authors measured subject body weight parameters at weeks $0,4,8$, and 12 . In study [9], it had subjects to come on days $0,12,36$, and 86 . In study [10] it only measured the subjects on the initial day 0 and after 1 month. In [10], it also had subjects who missed the follow-up.

Tea has historic significance with green tea gaining wide popularity with its advertisement as a weight reducing agent. It is made from the leaves of Camellia sinensis. Camellia sinensis undergo very minimum oxidation in the process, containing two very important constituents: catethine polyphenol and caffeine, Catethine polyphenol is involved in inhibiting an enzyme catecholo-methyl transferase (COMT) which in turn leads to enhanced action of catecholamines [11]. Caffeine is also involved in inhibiting phosphodiesterase induce degradation of Camp which causes an increased release of norepinephrine. Both caffeine and catethin polyphenol has potential to increase the energy expenditure which in turn can increase fat oxidation, leading to decrease in body weight. Catecholamines may also play an important role in satiety of the subject [12].

All the three studies used females as their primary subjects while [8], was the only study in which men were also in the their trail. All three studies used green tea in an extract capsule form. The specific timing and amount of extract used were slightly different. All placebos used are same and used a capsule of cellulose. In study [9], it also allowed their subjects to use caffeine during the trial period. The number of subjects used in all three studies was kept under hundred and trial lasted for about three 
months, while blinding was not compromised in all the three studies.

\section{Conclusions}

By reviewing all the three studies, it can be concluded that green tea does have some effect on weight reduction but it is not very significant plus significant variability between the intervention and placebo cannot be well defined. Green tea extract use was not harmful throughout the trail, further confirming the idea that it is not harmful to the body, but its weight reducing properties has to be further confirmed.

More research and investigation is also needed to determine the exact role of energy expenditure increase with the use of green tea. All the above three trails were done for a short duration of time. Trails are of long duration for further evaluation along with control of daily caloric intake and physical activity.

Long-term research with more participants and with better follow up protocols with exact statistics for this beneficial effect of green tea can be concluded, which would be of great help through a natural resource for weight reduction in overweight.

\section{Conflict of Interest}

The authors declare no conflict of interest.

\section{References}

[1] National Institutes of Health, National Heart LaBI, North American Association for the Study of Obesity. The practical guide: identification, evaluation, and treatment of overweight and obesity in adults.US Department of Health and Human Services, Public Health Service, National Institutes of Health, National Heart, Lung, and Blood Institute; 2000. NIH publication no. 00-4084.

[2] The Asia-Pacific Perspective Redefining Obesity; 2000.

[3] Wing RR, Hill JO. Successful weight loss maintenance. Annu Rev Nutr 2001;21:323-41

[4] Action of the AMA House of Delegates 2013 Annual Meeting: Recommendations in Report 3 of the Council on Science and Public Health Report Adopted, and Remainder of Report Filed.

[5] Obesity and Overweight. World Health Organization (WHO). 2010. Available http://www.who.int/dietphysicalactivity/publications/facts/obesity/en/. Accessed Sept 27, 2010.

[6] Overweight and Obesity. Centers for Disease Control. 2010. Available at: http://www.cdc.gov/obesity/recommendations.html. Accessed Sept 27, 2010.

[7] Cherry, D, Hing, E, Woodwell, D, et al. National Ambulatory Medical Care Survey: 2006 Summary. National Health Statistics Reports. 2008. Available at: http://www.cdc.gov/nchs/data/nhsr/nhsr003.pdf. Accessed Sept 28, 2010

[8] Auvichayapat P, Prapochanung M, Tunkamnerdthai O, et al. Effectiveness of green tea on weight reduction in obeseThais: A randomized, controlled trial. PhysiolBehav. 2008;93(3):486- 491.

[9] Diepvens K, Westerterp KR, Westerterp-Plantenga MS. Obesity and thermogenesis related to the consumption of caffeine, ephedrine, capsaicin and green tea. Am J Physiol Regul Integr Comp Physiol 2007;292:77-85.

[10] Hsu C, Tsai T, Kao Y, Hwang K, Tseng T, Chou P. Effect of green tea extract (GTE) on obese women: A randomized, double-blind, placebo-controlled clinical trial. Clinical Nutrition. 2008;27(3):363-370.

[11] Kovacs EM, Mela DJ. Metabolically active functional food ingredients for weight control. Obes Rev 2006;7:59-78.

[12] Chantre P, Lairon D. Recent findings of green tea extract AR 25 (Exolise) and its activity for the treatment of obesity. Phytomedicine 2002;9:3-8. 